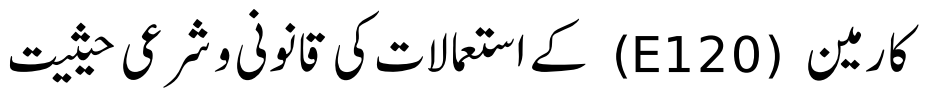

\section{Carmine (E120): A Study on its Legal and Juridical Status}

$$
\text { يابر فاروت }
$$

\begin{abstract}
:
Carmine, a color derived from an insect known as cochineal. Its scientific formula is E120. It is used in many types of food and cosmetics. Basically, it is a red color (red no 4) and after a chemical processes it assumes a new artificial color. The Europeans use this color according to their legal requirements. In Pakistan the use of the color as a food ingredient has been banned and many such products, in which this color has been added have also been discarded as some jurists have declared it as Haräm while other legitimize its use. The reason why some jurists considered it "Haräm" is purely because of its harmful nature which causes allergy and other harmful diseases, however, its external use like in cloth coloring and cosmetics is allowed. This study elaborates on the status and legal use of this color in the light of the opinions of the jurists.
\end{abstract}

Keywords: Carmine, Cochineal, Color, E120, (Pfa), Food Authority

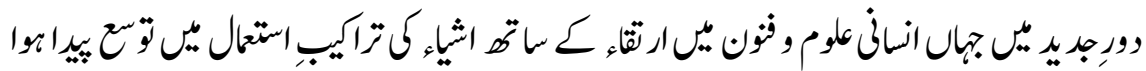

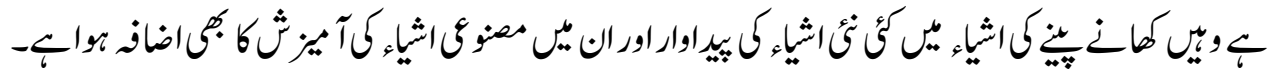

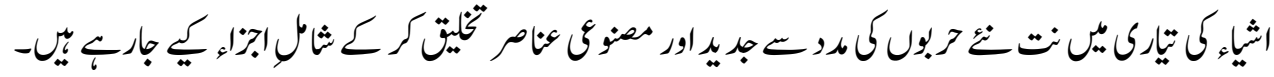

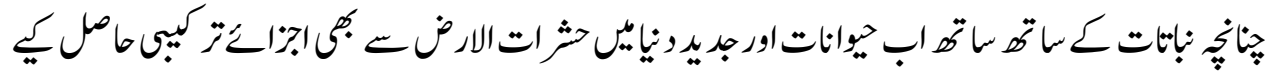

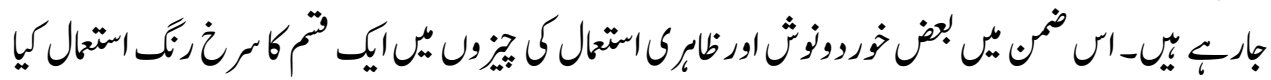

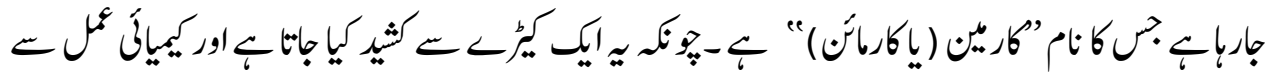

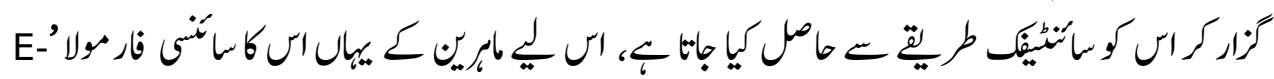

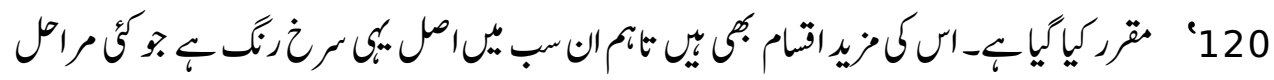

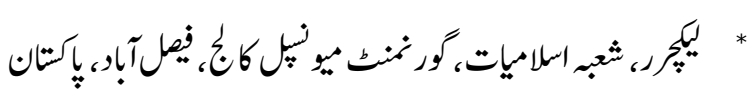




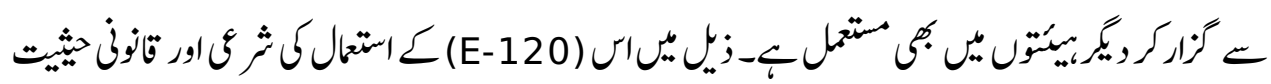

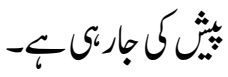

\section{مالقد تقيقات:}

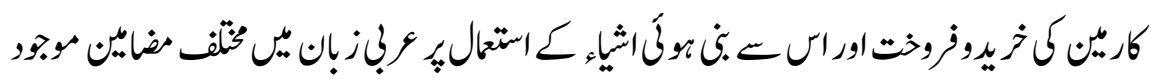

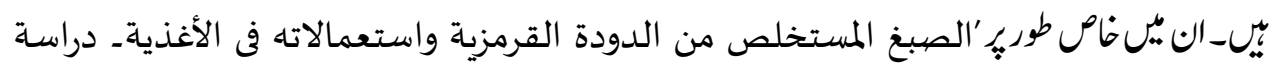

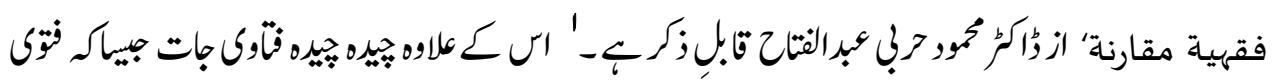

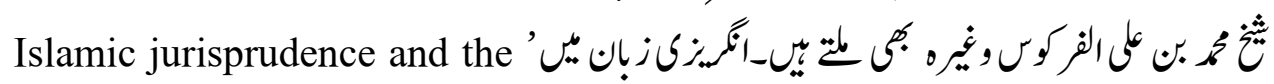
status of arthropods: as alternative source of protein and with regard to

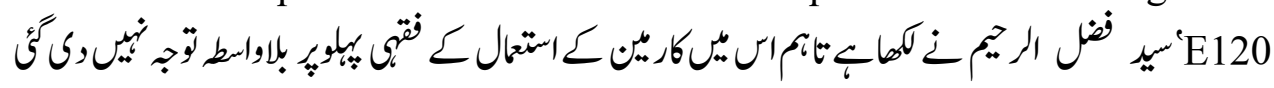

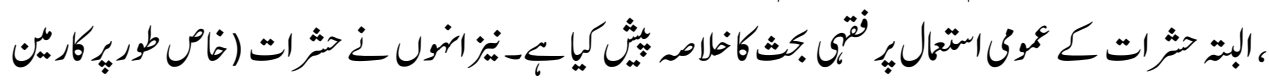

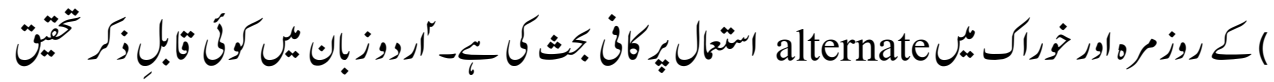

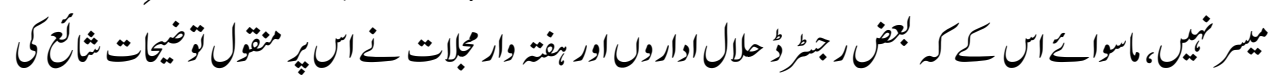

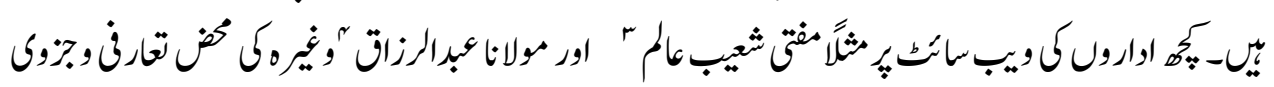

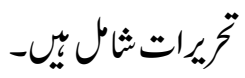
تخيتنكبيارى

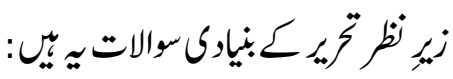

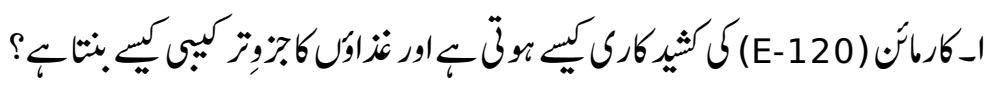

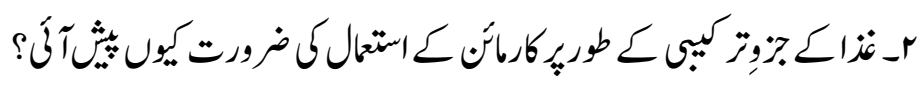

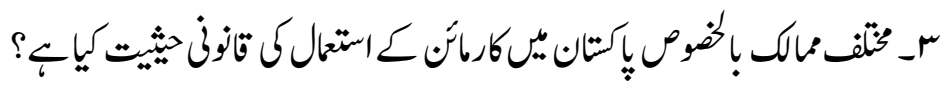

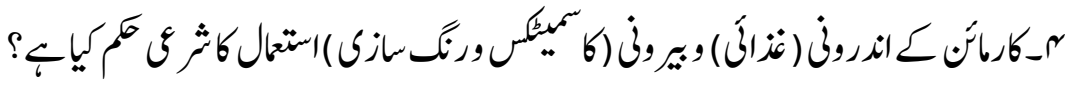

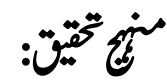

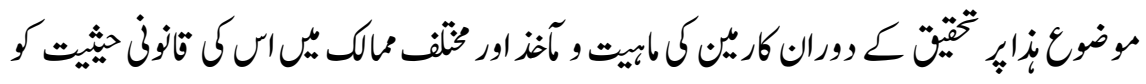

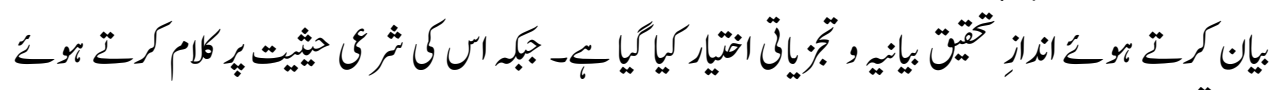

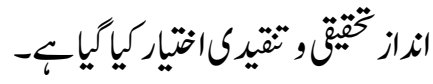




\section{كرهيط:كטافيت:}

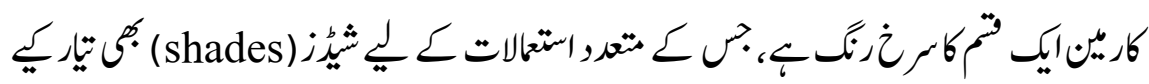

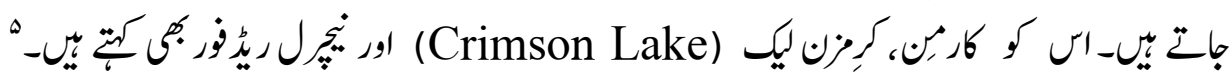

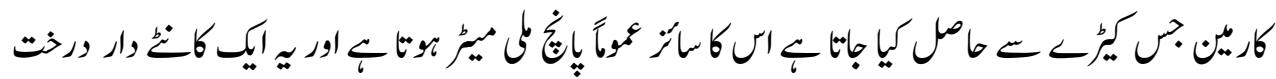
CCactus

Carmine, Red or purplish-red pigment obtained from cochineal (q.v.), a red dyestuff extracted from dried bodies of certain female scale insects native to tropical and subtropical America. ${ }^{6}$

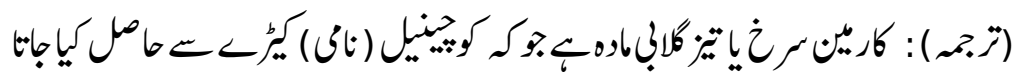

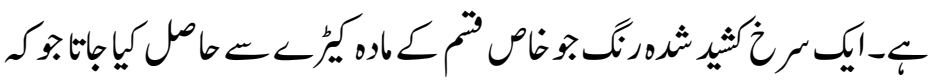

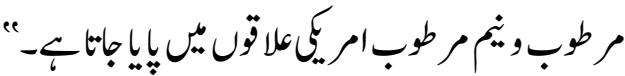

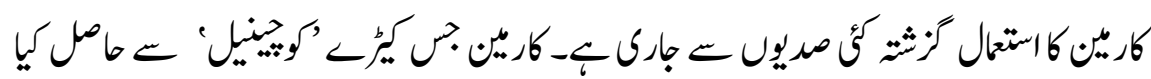

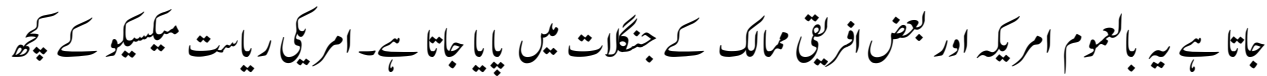

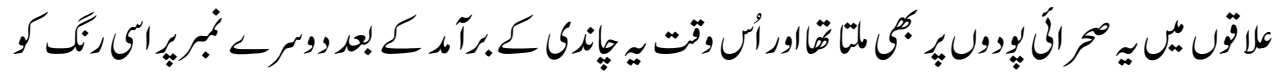

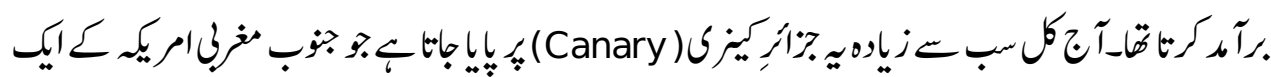

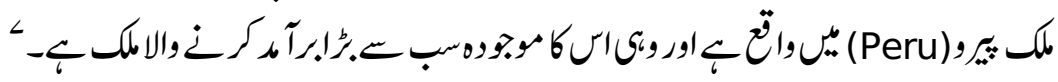

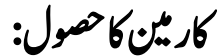

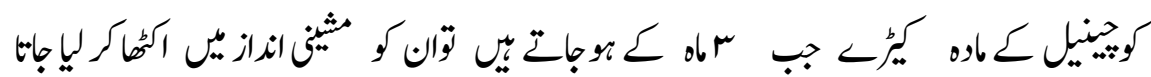

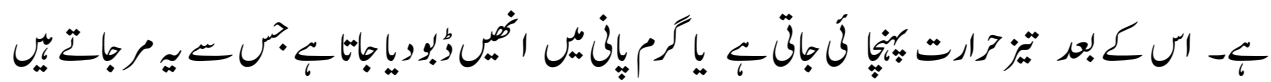

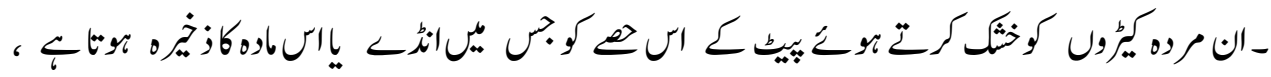

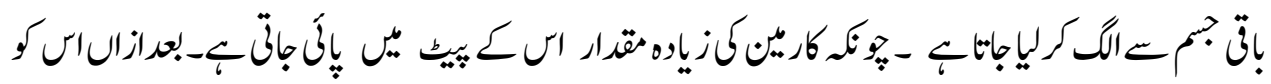

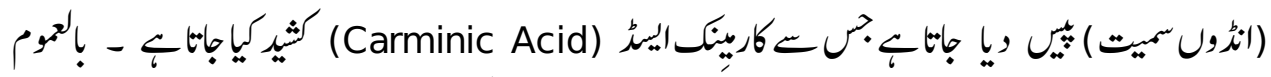

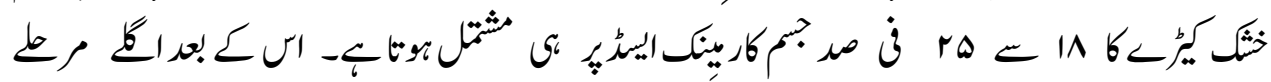

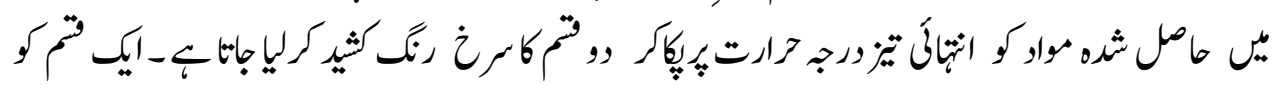

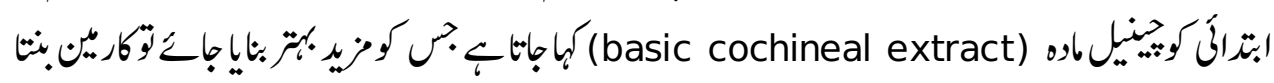




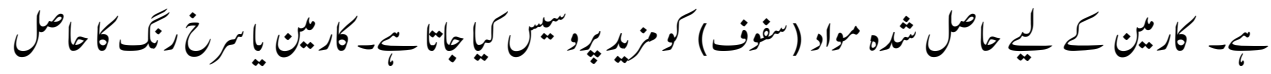

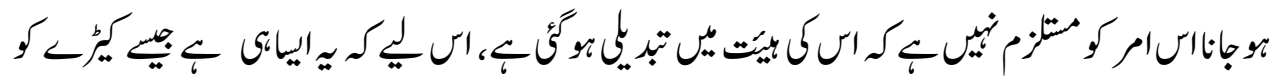

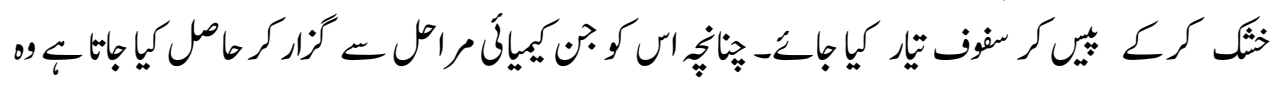

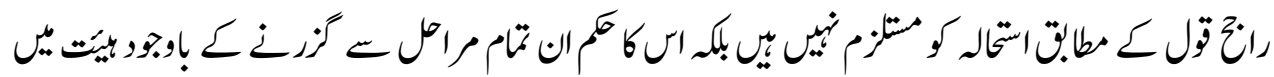

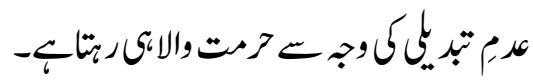

\section{كرئن ك استعالات:}

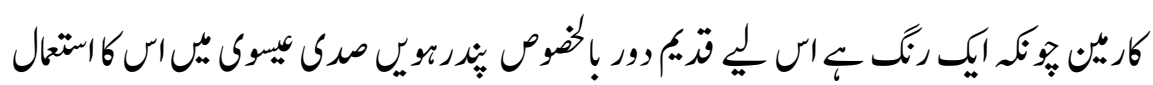

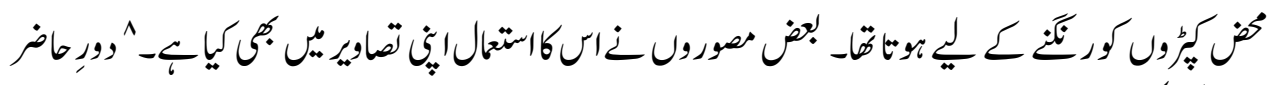

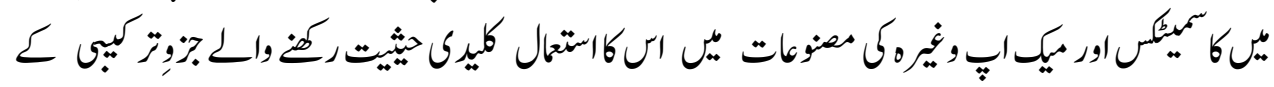

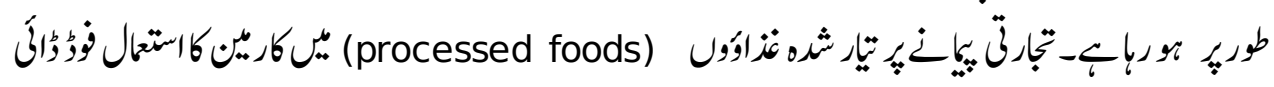

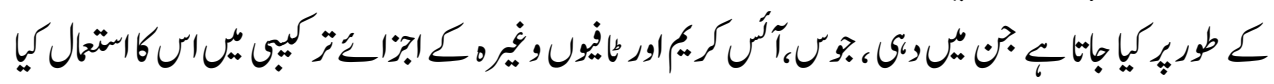

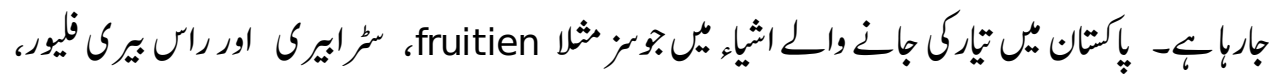

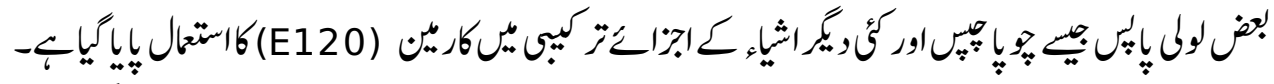

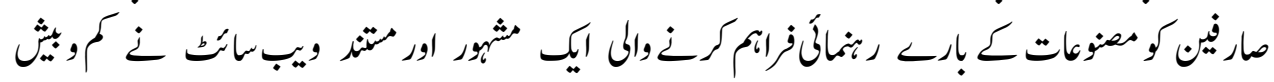

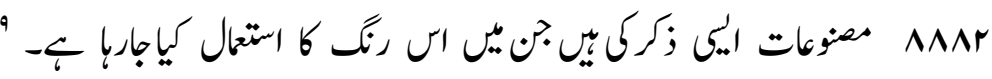

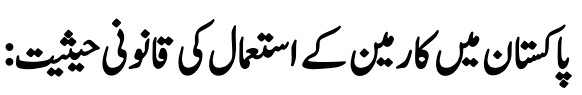

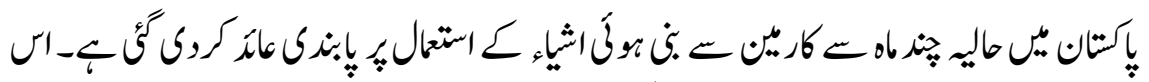

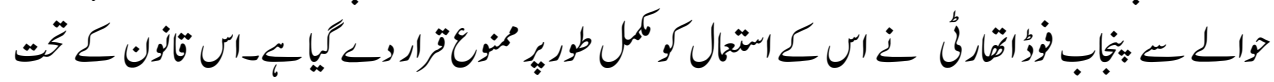

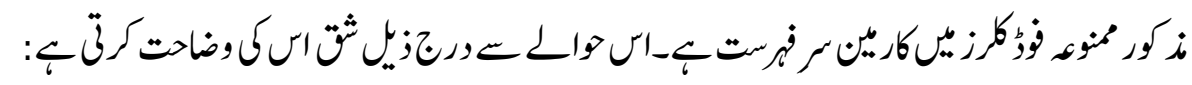

"Carmine (E-120), Shellac (E-904) and other colors mentioned in the prohibited substances table of these regulations are strictly banned for any usage in food manufacturing, processing and in any ingredients thereof." 10

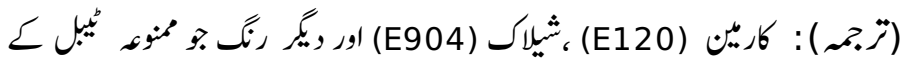

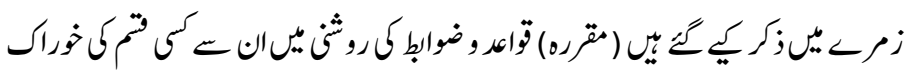

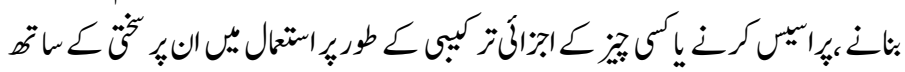

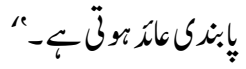


[ब]

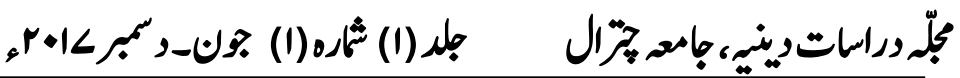

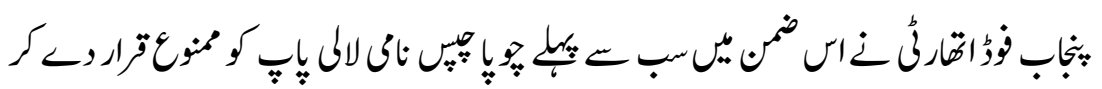

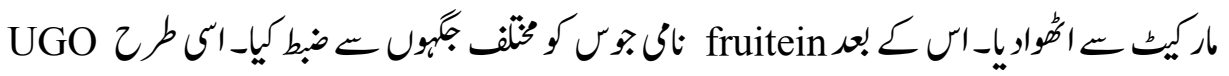

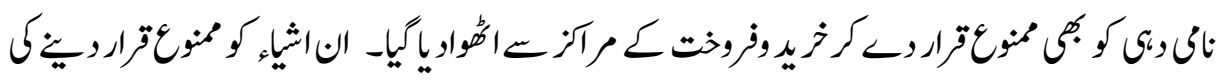

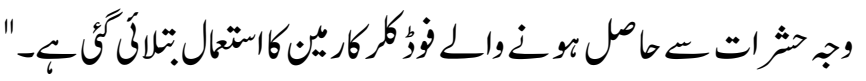

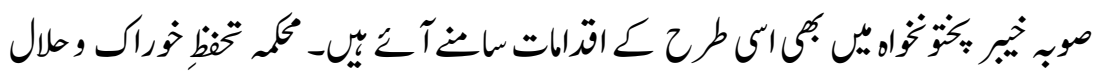

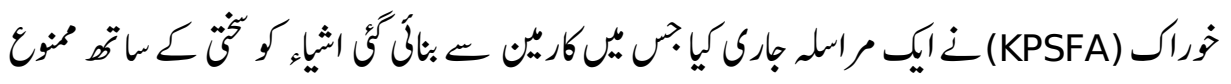

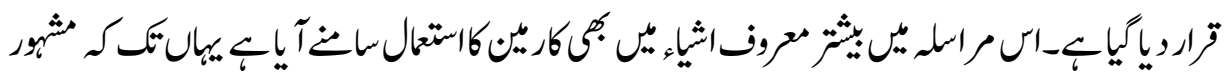

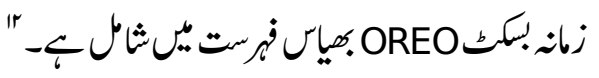

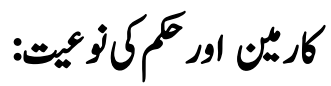

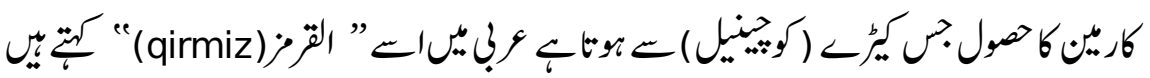

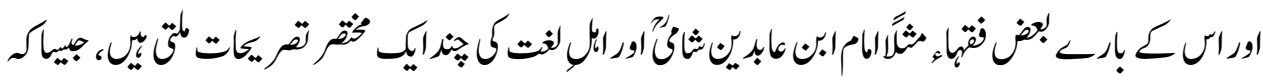

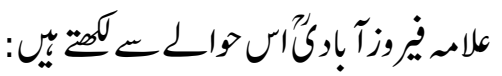

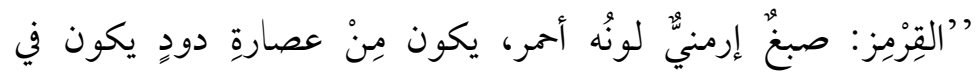

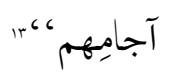

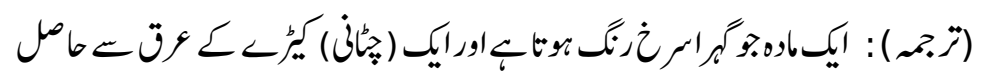

كياجابات4-

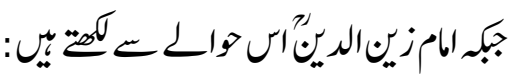

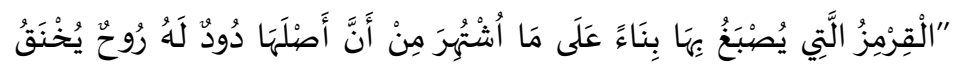

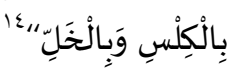

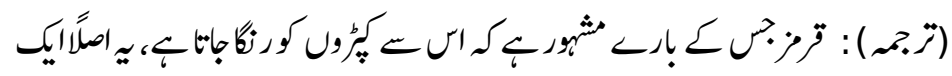

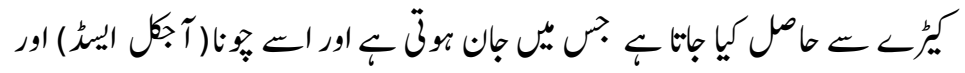

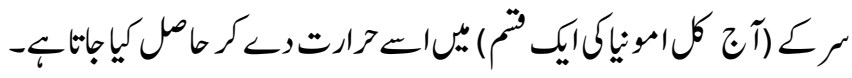

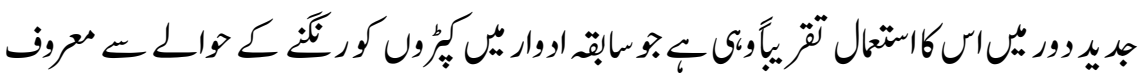

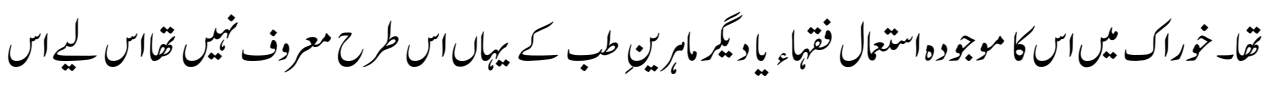

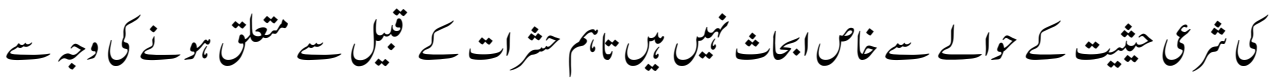

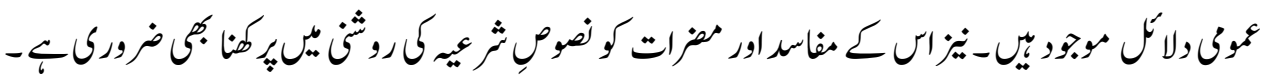




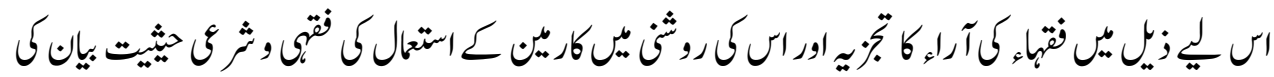
بإن

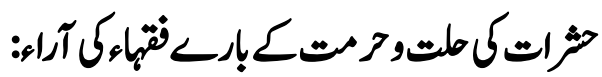

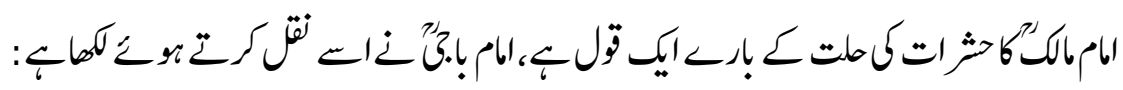

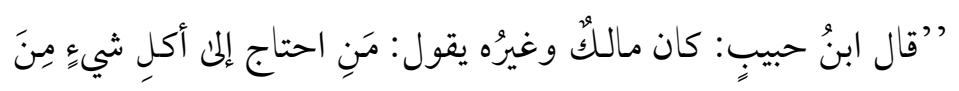

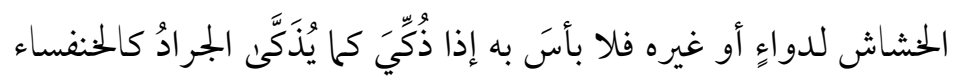

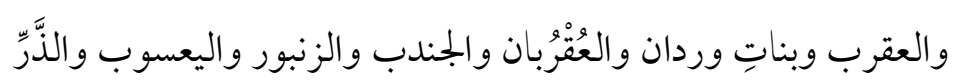

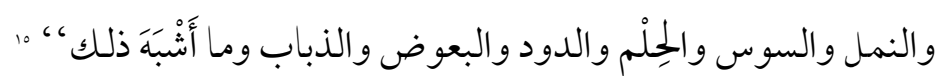

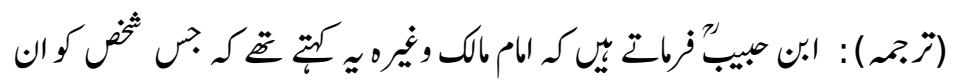

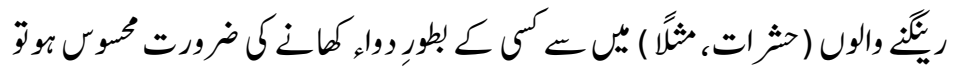

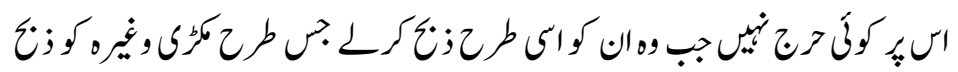

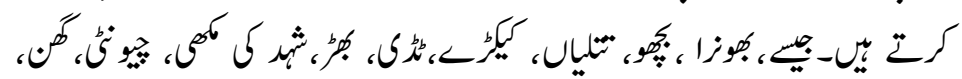

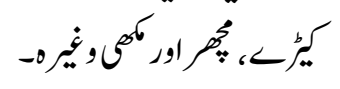

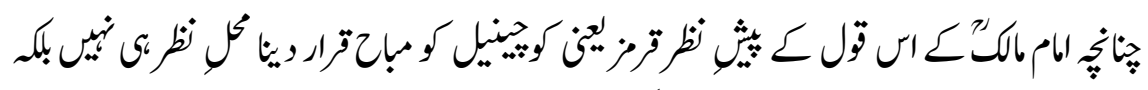

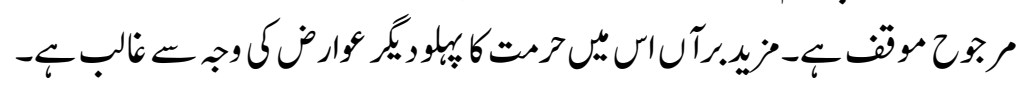

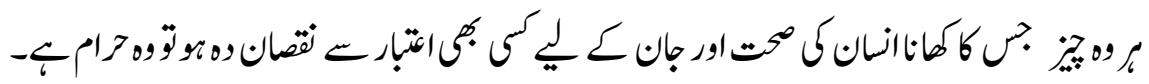

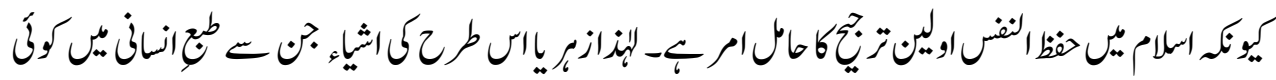

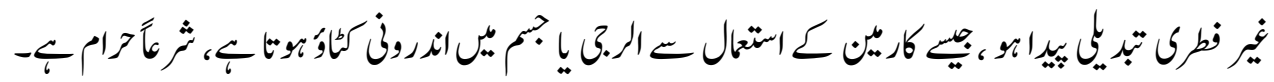

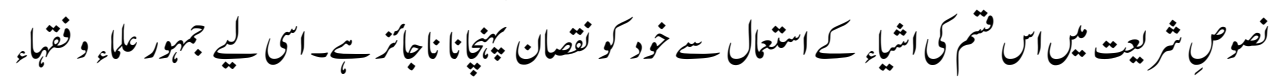

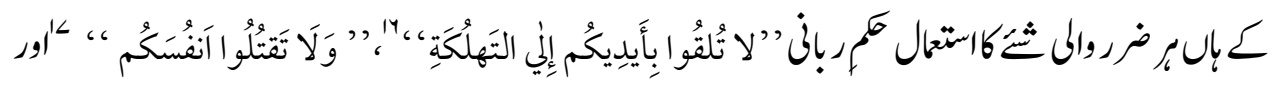

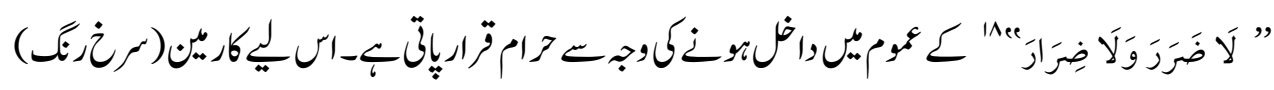

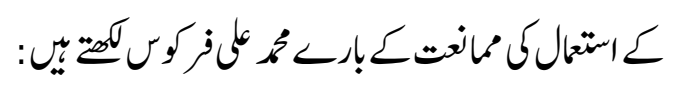

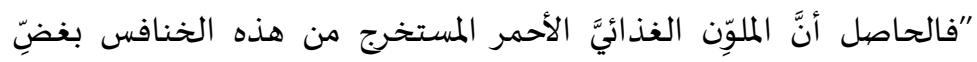

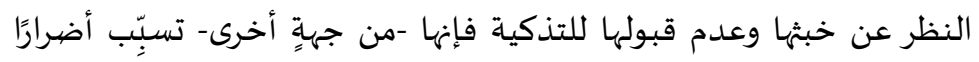

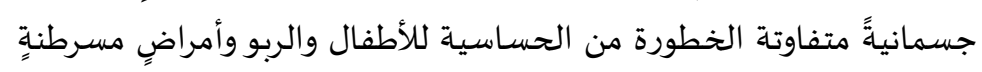


$[<]$

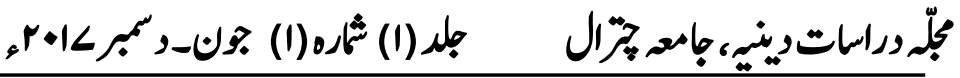

وغيرها من الأعراض والأمراض، لذلك تُمْنَع عملاً بقوله صلَّى الله عليه وسلَّم:

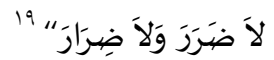

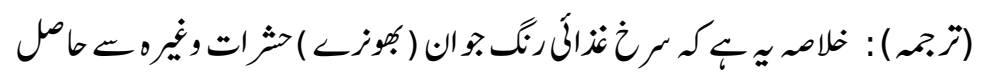

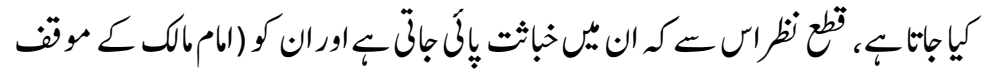

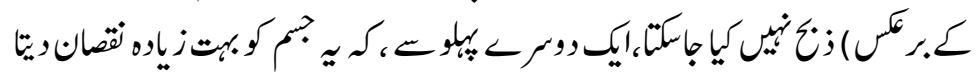

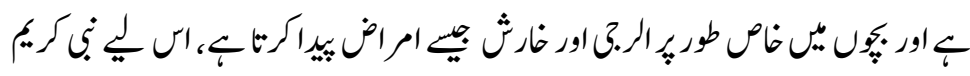

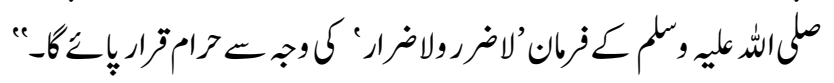

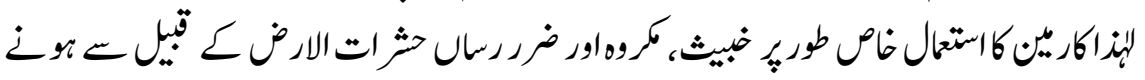

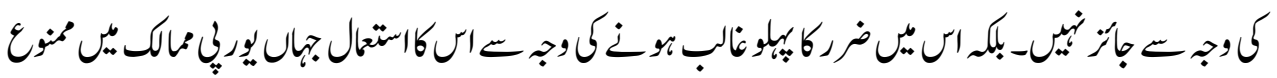

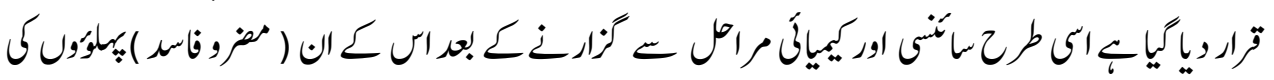

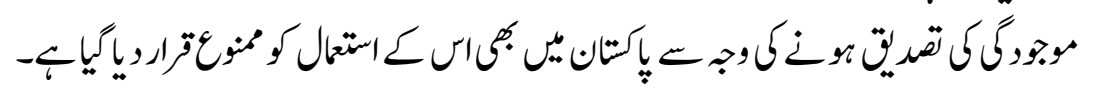

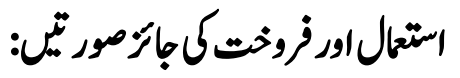

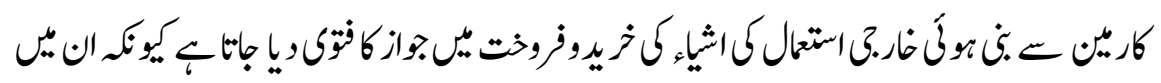

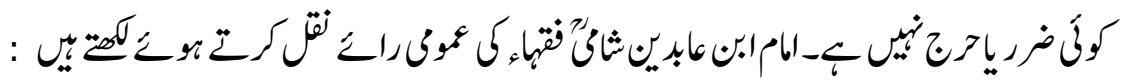

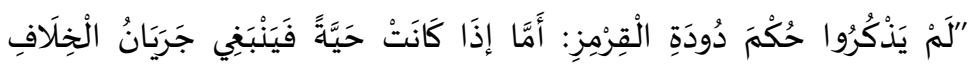

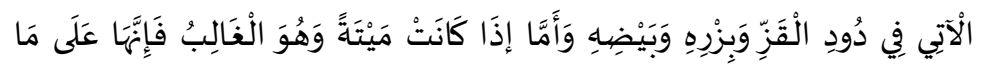

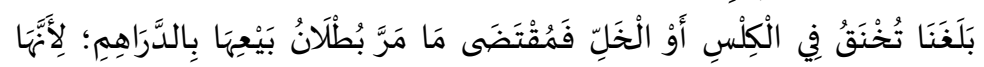

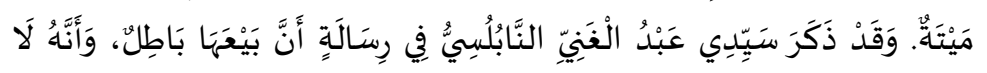

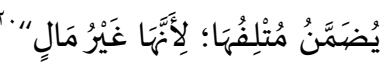

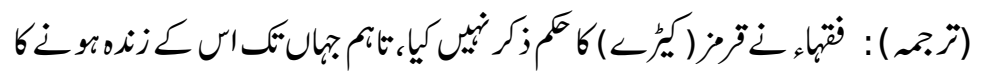

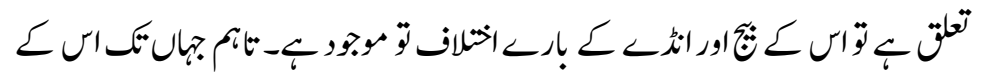

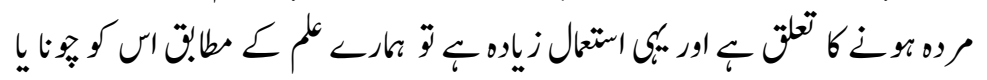

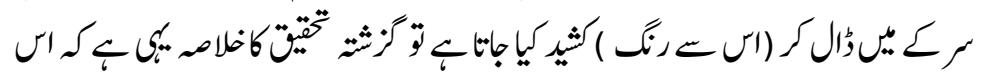

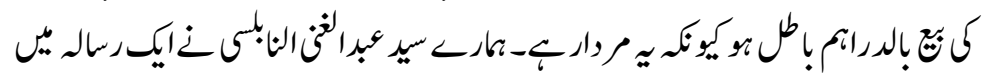

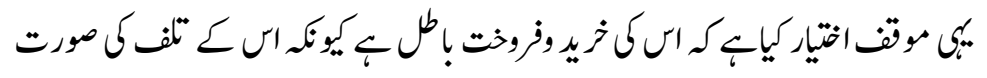

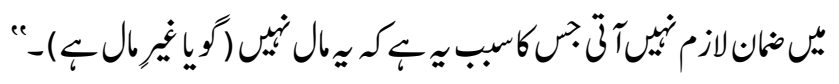


[ᄉ]

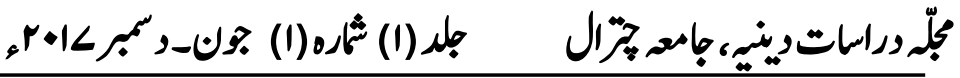

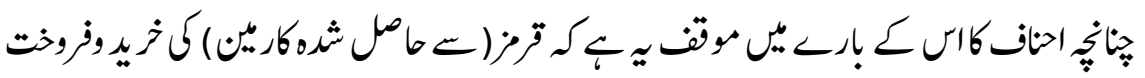

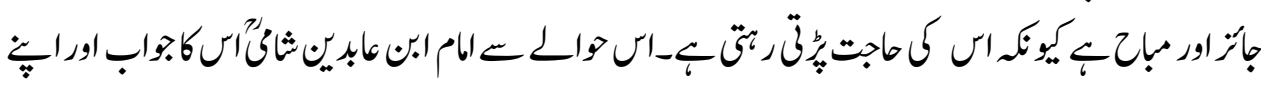

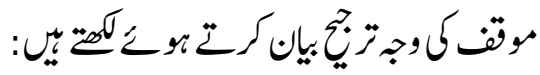

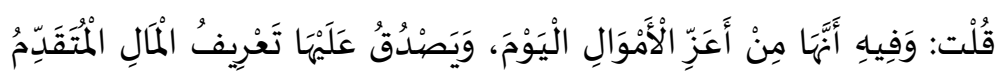

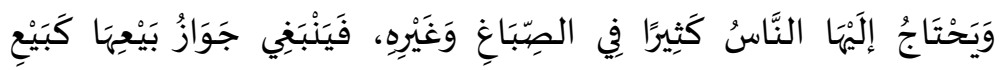

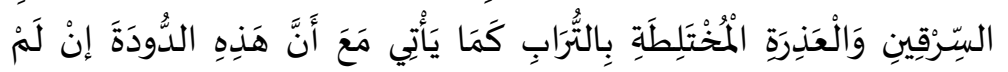

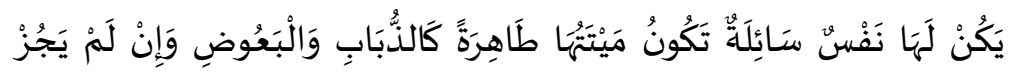

أَكَلََْا“'

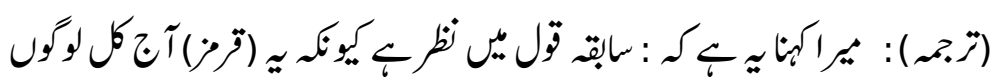

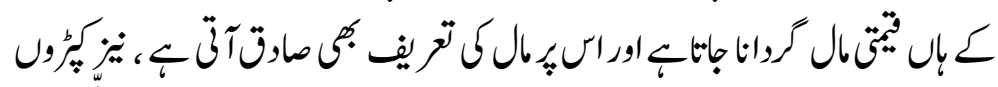

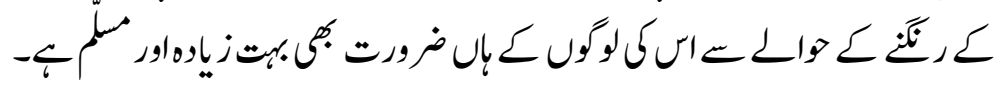

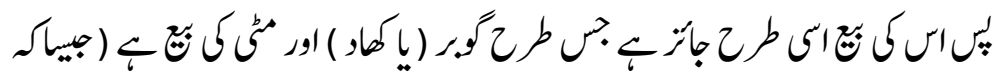

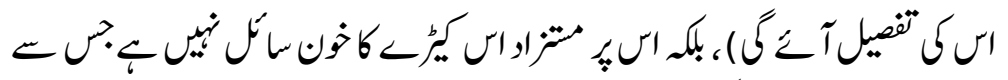

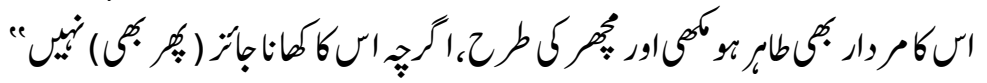

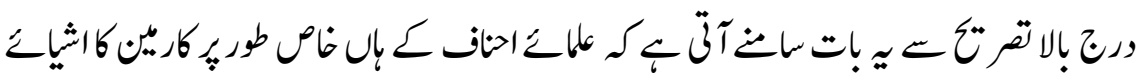

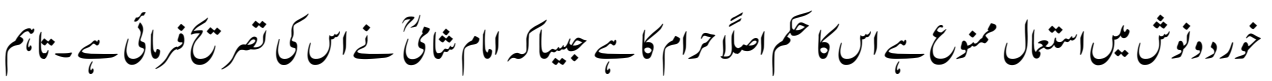

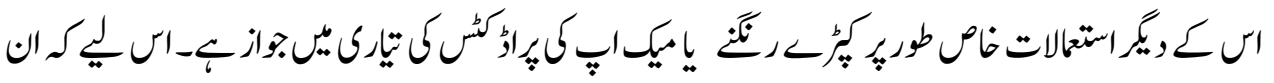

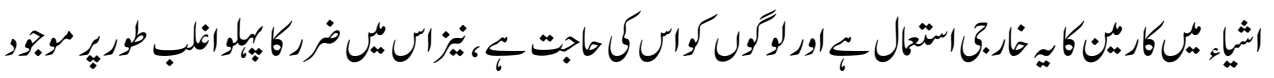

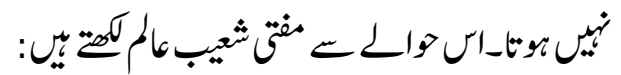

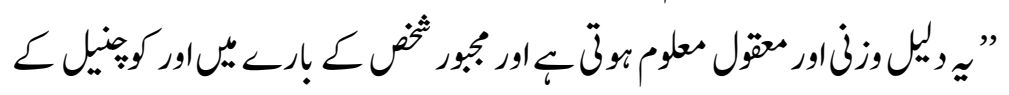

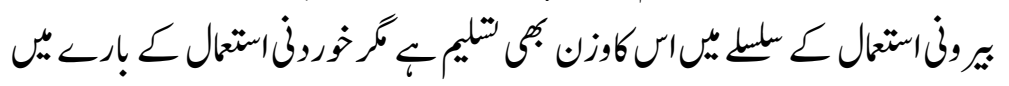

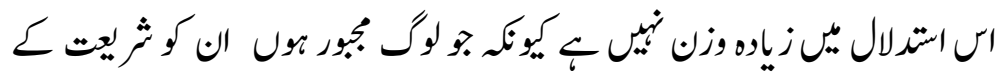

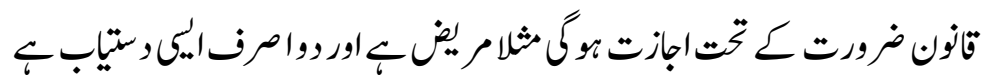

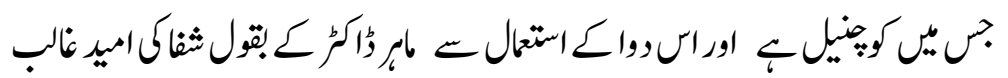

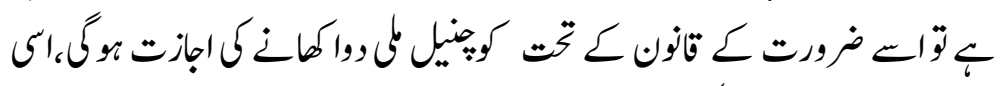

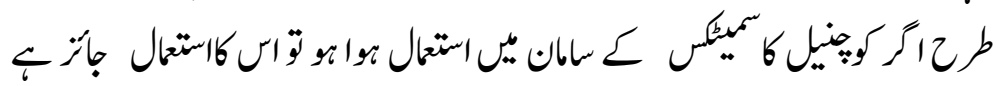

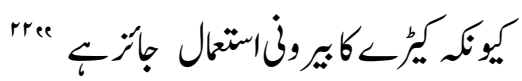




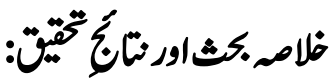

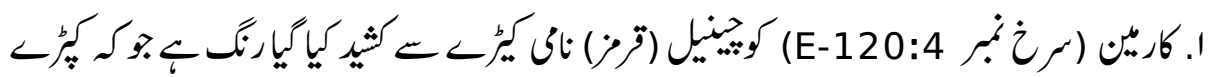

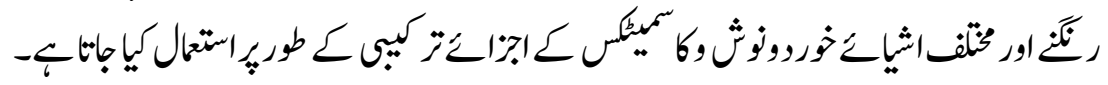

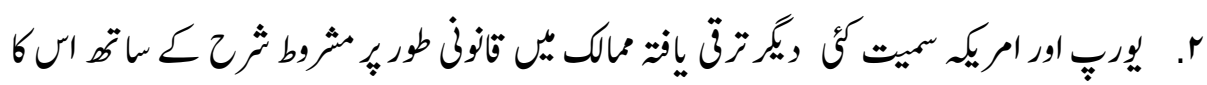

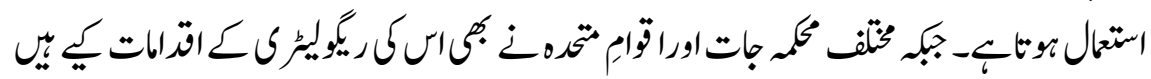

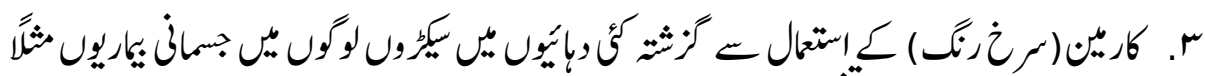

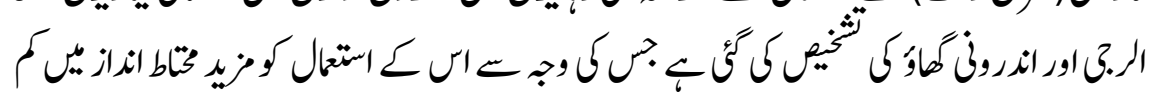

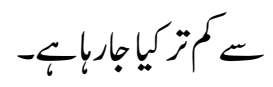

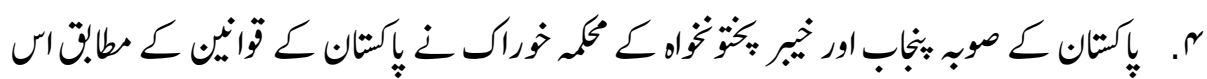

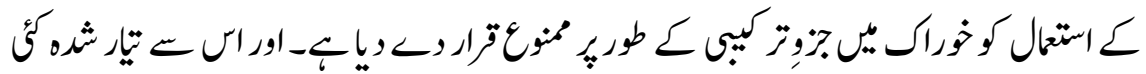

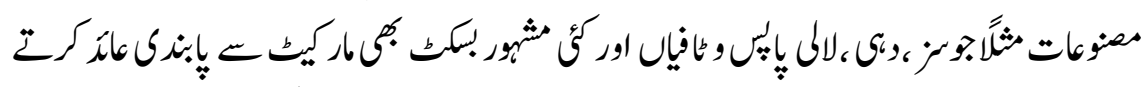

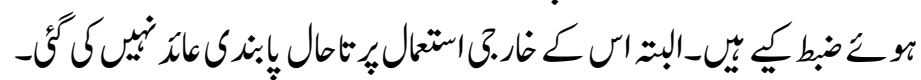

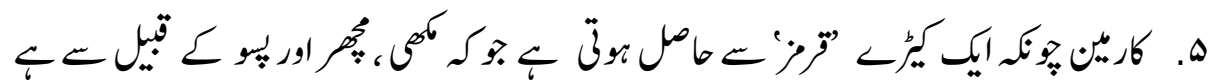

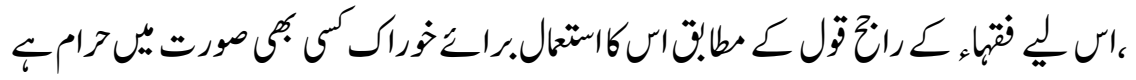

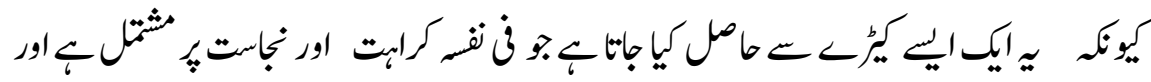

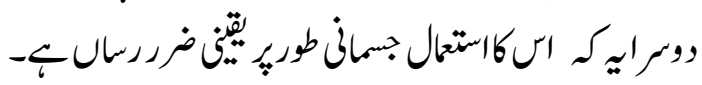

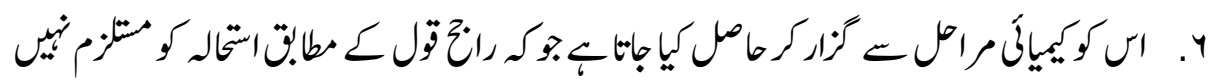

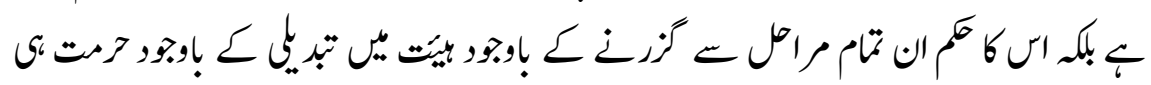
$-<$

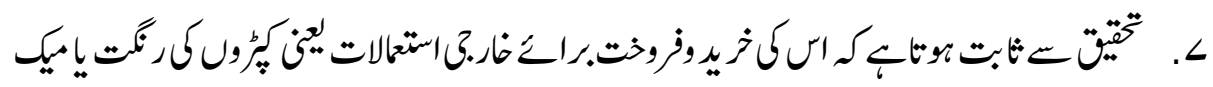

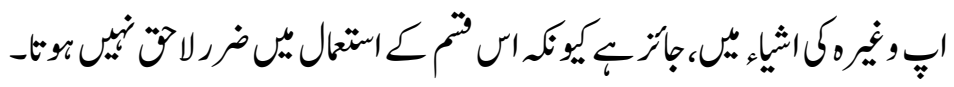

هاثَّوحاله جات

https://bfsa.journal.ekb. Accessed on July 6, 2019 at 09:30 am

Rahim SF. Islamic jurisprudence and the status of arthropods: as alternative source of protein and with regard to E120. MOJ Food Process Technol.2018:6 (4):330-340. DOI: $10.15406 /$ mojfpt.2018.06.00184 
http://www.tafheemeislam.com/article-details.php?id=MTM0

http://shariahandbiz.com/index.php/halal accessed; July, 6, 2019

5. Dapson, RW; Frank, M; Penney, DP; Kiernan, JA; Revised procedures

for the certification of carmine (C.I. 75470, Natural red 4) as a Biological stain,

Biotechnic \& Histochemistry (vol: 82, issue: 1), Biological Stain Commission, UK, 2007, p:13. https://doi.org/10.1080/10520290701207364

6. https://www.britannica.com/technology/carmine, accessed on January 21, 2019 at 03:30 pm

7.. https://web.archive.org/web/200903260600829 accessed on January 21, 2019 at $02: 40 \mathrm{pm}$

8. $\quad$ https://colorlex.com/project/tintorettu-portrait-of-vincenzo-accessed on January 21, 2019 at $03: 30 \mathrm{pm}$.

9. www.goodguide.com accessed on January 21, 2009 at 8:00 pm

10. Govt. of the Punjab (Law and Parliamentary Affairs Department), The Punjab

Gazette,: Punjab food authority, Lahore, June 06, 2018, p:8

11. http://www.pfa.gop.pk/latest-news/ accessed on January 22, 2019 at 04:55 pm

12. KPSFA, Peshawar, Vide: notification No: DG (KPFSA)/DT/493),

Dated: December 26, 2018.

$$
\begin{aligned}
& \text { "' . فيروزآبادى، علامه مجد الدين محمد بن يعقوب، القاموس المحيط، موسسة الرسالة، بيروت، } \\
& \text { Orl ص. . O O } \\
& \text { ابن نجيم المصرى، زين الدين بن ابرابيم بن محمد، البحر الرائق،دارالكتاب الاسلامى، مشق،ج ج } \\
& \text { 10 ص.7 } \\
& \text { الباجى،ابو الوليد سليمان بن خلف الاندلسى، المنتقى شرح الموطا،مطبعه السعادة، مصر، } \\
& \text { ج3، ص صa } 129 \\
& \text { سورة البقرة: مهاج } 190 \\
& \text { سورة النساء: مون }
\end{aligned}
$$

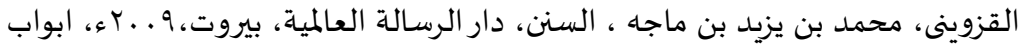

$$
\begin{aligned}
& \text { الاحكام، باب من بنى فى حقه ما يضر بجاره،رقم الحديث: .rr }
\end{aligned}
$$

19

http://www.kulalsalafiyeen.com/vb/showthread.php?t=45316, accessed on January 22, 2019 at 06:50 pm.

$$
\begin{aligned}
& \text { ابن عابدين الشامى، محمد أمين بن عمر بن عبدالعزيز،رد المحتار على الدر المختار، دارالفكر، }
\end{aligned}
$$

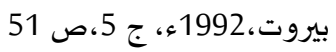

22. http://www.tafheemeislam.com/article-details.php?id=MTM0, Accessed on july 5, 2019 at $03: 30 \mathrm{pm}$.

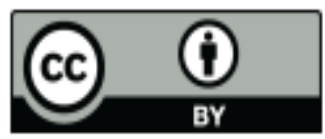

@ 2017 by the author, Licensee University of Chitral, Journal of Religious Studies. This article is an open access article distributed under the terms and conditions of the Creative Commons Attribution (CC BY) (http://creativecommons.org/licenses/by/4.0/). 